University of Nebraska - Lincoln

DigitalCommons@University of Nebraska - Lincoln

Center for Brain, Biology and Behavior: Papers \&

Publications

Brain, Biology and Behavior, Center for

2020

\title{
Males with chronic ankle instability demonstrate deficits in neurocognitive function compared to control and copers
}

Adam B. Rosen

Melanie L. McGrath

Arthur C. Maerlender

Follow this and additional works at: https://digitalcommons.unl.edu/cbbbpapers

Part of the Behavior and Behavior Mechanisms Commons, Nervous System Commons, Other Analytical, Diagnostic and Therapeutic Techniques and Equipment Commons, Other Neuroscience and Neurobiology Commons, Other Psychiatry and Psychology Commons, Rehabilitation and Therapy Commons, and the Sports Sciences Commons

This Article is brought to you for free and open access by the Brain, Biology and Behavior, Center for at DigitalCommons@University of Nebraska - Lincoln. It has been accepted for inclusion in Center for Brain, Biology and Behavior: Papers \& Publications by an authorized administrator of DigitalCommons@University of Nebraska Lincoln. 


\title{
Males with chronic ankle instability demonstrate deficits in neurocognitive function compared to control and copers
}

\author{
Adam B. Rosen, ${ }^{1}$ Melanie L. McGrath, ${ }^{2}$ \\ and Arthur L. Maerlender ${ }^{3}$
}

\footnotetext{
1 School of Health and Kinesiology, University of Nebraska at Omaha, Omaha, NE, USA

2 Department of Health and Human Performance, University of Montana, Missoula, MO, USA

3 Center for Brain, Biology and Behavior, University of Nebraska at Lincoln, Lincoln, NE, USA
Corresponding author - Adam B. Rosen, School of Health and Kinesiology, University of Nebraska at Omaha, 6001 Dodge St, HPER 207Y, Omaha, NE 68132, USA; arosen@unomaha.edu

\section{ORCID}

Adam B. Rosen http://orcid.org/0000-0002-1204-2289

\begin{abstract}
The purpose of this study was to determine if there were neurocognitive deficits among controls, copers and those with chronic ankle instability (CAI). Participants included those without history of ankle injury $(n=14)$, ankle sprain copers $(n=13)$ and patients with self-reported CAI $(n=14)$. They completed a battery of valid and reliable computer-based neurocognitive tests. The differences between neurocognitive domain scores were compared across the Control, Coper and CAI groups. Patients with CAI had lower composite memory, visual memory and simple attention compared to controls. In males with CAl, large differences in memory and attention were found relative to control participants. These differences may contribute
\end{abstract}

Published in Research in Sports Medicine (2020)

doi:10.1080/15438627.2020.1723099

Copyright (c) 2020 Informa UK Ltd, Taylor \& Francis Group. Used by permission. Submitted 15 May 2019; accepted 26 January 2020; published 29 January 2020. 
to uncontrolled episodes of giving way through deficits in spatial awareness and/ or an inability to identify environmental obstacles. Clinicians should explore ways to provide additional stimuli through innovative rehabilitation protocols aimed at maximizing neurocognitive abilities in patients with CAI.

Keywords: Central nervous system, attention, memory, CAl, functional ankle instability

\section{Introduction}

Ankle sprains are the most common musculoskeletal injury as well as the most frequent recurring injury in most sports (Roos et al., 2017; Welton et al., 2018). The cost to treat a single ankle sprain is approximately $\$ 1000$ with the overall burden on the US healthcare system estimated to be between four and six billion dollars due to the high frequency and recurrence rate of ankle injury (Shah, Thomas, Noone, Blanchette, \& Wikstrom, 2016). While a single ankle sprain causes significant pain and loss of function, approximately $40 \%$ of these patients develop a condition known as chronic ankle instability (CAI) (Hershkovich et al., 2015). Repetitive sprains, ankle "rolling" and significant self-reported disability characterize CAI. Repeated ankle sprains may contribute to the early onset of osteoarthritis (Valderrabano, Hintermann, Horisberger, \& Fung, 2006), decreased physical activity (Hubbard-Turner \& Turner, 2015), poorer quality of life (Houston, Hoch, \& Hoch, 2015) and increased self-reported disability (Rozen, Ko, \& Brown, 2016).

Many researchers posit that sensorimotor and neuromuscular function impairments likely cause and perpetuate the symptoms of CAI. However, deficiencies in neurocognitive function may be an additional factor that influences reinjury rates and plays a role in the progression to CAI. Decreased neurocognitive function appears to be related to the incidence of other musculoskeletal injuries. For example, individuals have greater rates of lower extremity injury after a concussion, which affects short and long-term cognitive function (Brooks et al., 2016; Lynall et al., 2017). In a prospective design, deficits in neurocognitive function were found in those who would suffer from a non-contact ACL injuries compared to matched controls over the course of an athletic season (Swanik, Covassin, Stearne, \& Schatz, 2007). Specifically, those who suffered from non-contact $A C L$ injuries demonstrated 
lower neurocognitive processing speed, visual memory, verbal memory and reaction time at the time of preseason testing (Swanik et al., 2007). Another recent prospective study found that a combination of factors, including verbalmemory and reaction time identified American football players who went on to suffer from a lower extremity injury (McDonald, Wilkerson, McDermott, \& Bonacci, 2019). However, there has been limited research on the impact of neurocognitive function on patients with CAl. Altering cognitive demands may change lower limb biomechanics in those with CAI, although the research in this area is mixed (Burcal, Needle, Custer, \& Rosen, 2019; Burcal \&Wikstrom, 2016; Hung \&Miller, 2016; Rahnama, Salavati, Akhbari, \& Mazaheri, 2010; Shiravi, Talebian, Hadian, \& Oliaie, 2017; Springer \& Gottlieb, 2017; Tavakoli, Forghany, \& Nester, 2016). In one study the addition of a cognitive task during single-leg balance impaired stability, while another study demonstrated no changes in postural control when cognitive load increased (Burcal \& Wikstrom, 2016; Rahnama et al., 2010). However, neither of these studies actually measured neurocognitive function as a variable that may influence postural stability. A recent study found a relationship between poorer self-regulation of attention and attentional control and decreased postural stability in individuals with CAl, which was not present in non-injured controls (Rosen et al., 2017). This suggests that underlying deficits in neurocognitive function may impact postural control, which may help explain the loss of stability experienced by patients with CAI.

Recent studies suggest that neurocognitive function may play a role in the development of musculoskeletal injury, but this relationship has not been established in patients with CAl (Brooks et al., 2016; Lynall et al., 2017; McDonald et al., 2019; Swanik et al., 2007). In addition, a population, termed "copers," has become a subset of interest in CAI populations (Hertel \& Kaminski, 2005). A "coper" is an individual that suffered from an initial ankle sprain, had a full recovery, and has not developed CAl. Copers have been identified as a useful group that may offer valuable insight as to why some individuals develop CAI, while others do not. Therefore, the purpose of this study was to determine if there were neurocognitive deficits among controls, copers and those with CAl using existing clinical tools. We believed those with CAI would have worse neurocognitive scores compared to control and coper participants. 


\section{Materials and methods}

\section{Participants}

This study was approved by the local institutional review board and all participants consented to study procedures prior to participation. Participants were recruited as a sample of convenience from the local university population and placed into one of three groups; control, coper or CAl. All participants were physically active defined as participating in $>90$ minutes or more of physical activity per week. Only males were included in this study to control for differences in prevalence of CAl and neurocognitive function between males and females (Covassin et al., 2006; Nazareth, Huang, Voyer, \& Newcombe, 2019; Tanen, Docherty, Van Der Pol, Simon, \& Schrader, 2014; Weiss, Kemmler, Deisenhammer, \& Margarete, 2008). Participants were entered into the control group if they had 1) no history of lateral ankle sprain, 2) no complaints of their ankle giving way, and 3) a Cumberland Ankle Instability Tool (CAIT) score $\geq 28$, indicating good function (Hiller, Refshauge, Bundy, Herbert, \& Kilbreath, 2006). Ankle sprain coper inclusion criteria were 1) a history of a moderate to severe ankle sprain including inflammatory symptoms (pain, swelling, and/or discoloration) and disruption of desired physical activity, 2) 1 or fewer episodes of

giving way at the ankle in the previous 12 months, and 3) CAIT score $\geq 28$ (Hiller et al., 2006; Wikstrom \& Brown, 2014). Inclusion criteria for the CAl group were included: 1 ) a history of a moderate to severe ankle sprain including inflammatory symptoms (pain, swelling, and/or discoloration) and disruption of desired physical activity, 2) 2 or more episodes of giving way at the ankle in the previous 12 months, and 3) CAIT score $\leq 24$, suggesting decreased ankle function (Gribble et al., 2014). All participants were excluded with any of the following: history of lower extremity surgery or fracture; current sign or symptom of a joint sprain in the lower extremity (including pain, swelling, discoloration, or loss of range of motion or strength); any other health issue or unusual symptom (e.g. nausea, dizziness) that could affect the participant's safety or performance; diagnosis of a vestibular disorder; history of condition that impaired cognitive function such as learning disability, concussion, etc.; or if they were taking medications that affected cognitive function such as narcotics, anti-depressants, or anti-anxiety agents. 


\section{Procedures}

Participants first completed injury history questionnaires, CAIT and informed consent documentation. Participants then sat in a quiet room and completed the CNS Vital Signs (CNSVS, CNS Vital Signs LLC., Morrisville, NC, USA) on a laptop computer with a wireless mouse. The CNSVS is a common clinically and commercially available tool. It consists of a battery of valid and reliable computer-based neurocognitive tests designed to assess standard neuropsychological domains (Gualtieri \& Johnson, 2006). The CNSVS battery includes the Verbal Memory, Visual Memory, Finger Tapping, Symbol Digit Coding, Stroop, Shifting Attention and the Continuous Performance tests. The complete standard test took approximately 25 minutes to complete.

The Verbal Memory Test assessed both immediate and delayed recall of words. During the Verbal Memory Test, the participant was presented with 15 words for 2 seconds each. The participant then has to select the previously presented words, randomly presented along with 15 distractors. For delayed recall, the participant completed this process again after six neurocognitive tests. The Visual Memory test was completed using the same process as the Verbal Memory Test, however it uses shapes instead of words.

The Finger Tapping Test tested fine motor control and motor speed. The participant completed one practice trial and three test trials for the Finger Tapping Test. For the Finger Tapping Test, the participant tapped on the space bar as many times as possible for $10 \mathrm{~s}$.

The Symbol Digit Coding was a test of complex information processing and assesses complex attention, visual-perceptual speed and information processing. During the Symbol Digit Coding, the participant viewed an answer key with a row of symbols corresponding to the numbers 2 through 9. In a 2nd row below, the symbols are scrambled and provided in a random order, and the participant typed the corresponding number from the answer key.

The Stroop Test assessed inhibitory control, processing speed and executive skills accounting for complex and simple reaction time. The Stroop Test was a three part test where the participant was presented with the words red, yellow, blue and green. In the first part, the words (red, yellow and green) appeared only in black, once the word appeared the participant pressed the space bar as quickly as possible. In the second part, the participant was presented with the words in 
colour, the participant was supposed to only press the space bar when the word and colour matched. The last part, the participant pressed the space bar when the word and colour displayed did not match.

The Shifting Attention Test assesses executive function and reaction time. Participants were presented with a square or circle, coloured red or blue in a triangular fashion. The participant was asked to match one of the bottom shapes to the top shape by either shape or colour depending on the instructions provided to the participant.

The Continuous Performance Test measures sustained attention, choice reaction time and impulsivity. The participants were presented one at a time with random letters with 200 letters in total, approximately $1.5 \mathrm{~s}$ each. Participants responded only to the letter " $B$ " ( 40 times randomly) while ignoring all other letters as the letters contuined to appear sequentially regardless of response.

\section{Data and statistical analysis}

Upon completion of the CNSVS, a standard output report from the software provided age normalized, standard individual scores of various neurocognitive domains. Variables assessed from the CNS vital signs included an overall neurocognitive index as well as standardized individual domains of composite memory, verbal memory, visual memory, psychomotor speed, reaction time, complex attention, cognitive flexibility, processing speed, executive function, simple attention, and motor speed. Detailed information on how each score is calculated and normalized has been previously established and reported (Gualtieri \& Johnson, 2006). In the clinical reports (Figure 1), scores are categorized as "above average", "average", "low-average", "low", and "very low". These were assessed by frequencies and percentages by domain and group.

All statistical analyses were performed in the Statistical Package for the Social Sciences ${ }^{\mathrm{TM}} 24.0$ (SPSS, Inc., Chicago, IL). All neurocognitive dependent variables were first assessed via Kolmogorov-Smirnov tests to assess if scores fit a normal distribution. Variables with normal distributions were then evaluated with analyses of variance (ANOVA). Tukey's post hoc testing was used to determine differences in neurocognitive variables between control, coper and CAI participants with normal distributions. Variables with non-normal distributions were assessed via Kruskal-Wallis non-parametric tests with Mann-Whitney 


\begin{tabular}{|c|c|c|c|c|c|c|c|c|c|}
\hline Patient Profile & \begin{tabular}{|l} 
Percentil \\
Standard \\
\end{tabular} & $\begin{array}{l}\text { Range } \\
\text { Score Rang }\end{array}$ & & & $\begin{array}{l}>74 \\
>109\end{array}$ & \begin{tabular}{|c|}
$25-74$ \\
$90-109$ \\
\end{tabular} & $\begin{array}{c}9-24 \\
80-89\end{array}$ & $\begin{array}{c}2-8 \\
70-79\end{array}$ & $\begin{array}{l}<2 \\
<70\end{array}$ \\
\hline Domain Scores & $\begin{array}{l}\text { Patient } \\
\text { Score }\end{array}$ & $\begin{array}{c}\text { Standard } \\
\text { Score }\end{array}$ & Percentile & $\begin{array}{l}\text { Valid } \\
\text { Score }^{\star \star}\end{array}$ & Above & Average & $\begin{array}{c}\text { Low } \\
\text { Average }\end{array}$ & Low & $\begin{array}{l}\text { Very } \\
\text { Low }\end{array}$ \\
\hline Neurocognitive Index (NCl) & NA & 93 & 32 & Yes & & $\mathrm{x}$ & & & \\
\hline Composite Memory & 87 & 75 & 5 & Yes & & & & $\mathrm{x}$ & \\
\hline Verbal Memory & 47 & 79 & 8 & Yes & & & & $x$ & \\
\hline Visual Memory & 40 & 79 & 8 & Yes & & & & $\mathrm{X}$ & \\
\hline Psychomotor Speed & 201 & 110 & 75 & Yes & $\mathrm{X}$ & & & & \\
\hline Reaction Time $^{\star}$ & 585 & 102 & 55 & Yes & & $\mathrm{x}$ & & & \\
\hline Complex Attention* & 11 & 86 & 18 & Yes & & & $\mathrm{x}$ & & \\
\hline Cognitive Flexibility & 45 & 92 & 30 & Yes & & $\mathrm{x}$ & & & \\
\hline Processing Speed & 54 & 86 & 18 & Yes & & & $\mathrm{X}$ & & \\
\hline Executive Function & 47 & 94 & 34 & Yes & & $\mathrm{x}$ & & & \\
\hline Simple Attention & 38 & 85 & 16 & Yes & & & $\mathrm{x}$ & & \\
\hline Motor Speed & 142 & 120 & 91 & Yes & $\mathrm{x}$ & & & & \\
\hline
\end{tabular}

Figure 1. Sample CNS vital signs output from a chronic ankle instability participant.

$U$ tests for follow-up post hoc analysis. Statistical significance for all tests were set a-priori to $p=.05$. Cohen's $d$ effect sizes (ES) were also calculated for comparisons with normal distributions, and were interpreted as 0.2-0.5 = small, 0.5-0.8 moderate, and $>0.8$ as large, respectively (Cohen, 1992). For non-normally distributed variables the ES was calculated from the $z$-score as $r$ and interpreted as $0.1-0.3=$ small, 0.3-0.5 moderate, and >0.5 as large, respectively (Field, 2005; Fritz, Morris, \& Richler, 2012).

\section{Results}

Demographic data are presented in Table 1 for the three groups. Neurocognitive indices, which were normally distributed included

Table 1. Demographic data of the control, coper and chronic ankle instability (CAI) participants.

\begin{tabular}{lccc} 
& $\begin{array}{c}\text { Control } \\
(n=14)\end{array}$ & $\begin{array}{c}\text { Coper } \\
(n=13)\end{array}$ & $\begin{array}{c}\text { CAI } \\
(n=14)\end{array}$ \\
\hline Age (years) & $22.6 \pm 2.4$ & $22.2 \pm 2.4$ & $22.1 \pm 3.2$ \\
Mass $(\mathrm{kg})^{*}{ }^{+}$ & $85.1 \pm 12.3$ & $81.1 \pm 9.8$ & $84.0 \pm 12.5$ \\
Height $(\mathrm{cm})$ & $179.1 \pm 7.6$ & $179.5 \pm 8.5$ & $178.1 \pm 6.4$ \\
CAIT $^{*}{ }^{+}{ }^{+}$ & $29.8 \pm 0.4$ & $29.0 \pm 0.9$ & $16.0 \pm 5.8$ \\
Time since initial sprain (months) $_{\text {Number of ankle sprains }(n)^{*}}$ & NA & $27.2 \pm 29.0$ & $23.8 \pm 25.9$ \\
& NA & $1.4 \pm 0.5$ & $4.4 \pm 3.0$ \\
\hline
\end{tabular}

* indicates significant difference between control and CAI groups $(p<.05)$

+ indicates significant difference between coper and CAI groups $(p<.05)$

CAI = Chronic Ankle Instability

CAIT = Cumberland Ankle Instability Tool

NA = Not applicable 
Table 2. Neurocognitive indices across the control, coper, and CAl groups.

\begin{tabular}{|c|c|c|c|c|c|c|}
\hline \multirow{2}{*}{$\begin{array}{l}\text { Normally } \\
\text { Distributed Variables }\end{array}$} & \multicolumn{2}{|c|}{ Control } & \multicolumn{2}{|c|}{ Coper } & \multicolumn{2}{|l|}{$C A l$} \\
\hline & Mean (SD) & $95 \% \mathrm{Cl}$ & Mean (SD) & $95 \% \mathrm{Cl}$ & Mean (SD) & $95 \% \mathrm{Cl}$ \\
\hline Neurocognitive Index & $104.2(6.6)$ & 100.0-108.3 & $99.3(13.8)$ & $96.7-107.9$ & $99.8(7.2)$ & $95.6-104.0$ \\
\hline Composite Memorya & $112.5(14.5)$ & 103.3-121.7 & $100.5(14.0)$ & $91.4-110.0$ & $96.7(15.2)$ & $87.9-105.5$ \\
\hline Verbal Memory & $106.0(18.7)$ & $94.1-117.9$ & $101.1(16.7)$ & $90.4-112.4$ & $92.4(18.2)$ & $81.9-102.9$ \\
\hline Visual Memory ${ }^{a, c}$ & $115.0(11.8)$ & $107.5-122.5$ & $100.2(11.4)$ & $89.8-110.3$ & $101.4(12.0)$ & $94.4-108.3$ \\
\hline Processing Speed & $105.1(26.3)$ & $88.4-121.8$ & $105.0(18.5)$ & $94.2-118.2$ & $101.2(16.2)$ & $91.9-110.6$ \\
\hline Reaction Time & $95.8(11.4)$ & 88.5-103.0 & $98.7(14.2)$ & $93.6-108.6$ & $100.7(9.5)$ & $106.2-100.9$ \\
\hline Complex Attention & $100.8(10.0)$ & $94.4-107.1$ & $98.4(6.8)$ & $94.1-102.7$ & $94.6(15.6)$ & $85.6-103.6$ \\
\hline Cognitive Flexibility & $100.3(6.6)$ & $96.1-104.5$ & $95.5(11.5)$ & $91.7-103.4$ & $97.4(12.4)$ & $90.2-104.5$ \\
\hline Motor Speed & $110.6(19.9)$ & $98.0-123.2$ & $114.6(12.2)$ & $106.7-122.9$ & $110.6(18.1)$ & $100.1-121.0$ \\
\hline \multirow{2}{*}{$\begin{array}{l}\text { Non-Normally } \\
\text { Distributed Variables }\end{array}$} & \multicolumn{2}{|c|}{ Control } & \multicolumn{2}{|l|}{ Coper } & \multicolumn{2}{|c|}{$C A I$} \\
\hline & Median (IQR) & $95 \% \mathrm{Cl}$ & Median (IQR) & $95 \% \mathrm{Cl}$ & Median (IQR) & $95 \% \mathrm{Cl}$ \\
\hline Executive Function & $101.5(91.8-106.5)$ & $98.3-105.4$ & $99.5(91.0-106.3)$ & $92.7-104.3$ & 97.5 (93.3-108.3) & $91.9-105.9$ \\
\hline Psychomotor Speed & $103.0(99.0-127.8)$ & $95.8-125.4$ & $108.5(102.5-133.3)$ & $103.8-124.9$ & $110.0(98.3-119.8)$ & $100.0-118.7$ \\
\hline Simple Attentiona & $108.0(99.0-108.0)$ & $99.3-108.9$ & $96.0(90.8-108.0)$ & $89.8-103.4$ & $93.5(85.0-97.0)$ & 81.9-98.3 \\
\hline
\end{tabular}

a. indicates significant difference between control and CAI groups $(p<.05)$

b. indicates significant difference between control and coper groups $(p<.05)$

$\mathrm{CAI}=$ Chronic Ankle Instability, IQR = Interquartile Range

composite memory, verbal memory, visual memory, reaction time, complex attention, cognitive flexibility, processing speed, and motor speed. Non-normally distributed domains were psychomotor speed, executive function and simple attention. Descriptive statistics for each of the domains are located in Table 2.

Significant differences across groups were present for composite memory $(F=4.157, p=0.024)$, visual memory $(F=4.799, \mathrm{p}=0.014)$ and simple attention $\left(X^{2}=9.581, p=0.008\right)$. Follow-up tests revealed that those with CAI had lower composite memory $(t=2.748, p=$ 0.024 , ES $=1.06$, Figure 2(a)), visual memory $(t=2.898, p=0.038$, ES $=1.13$, Figure $2(b)$ ) and simple attention (Mann-Whitney $U=29.0, p$ $=0.003, \mathrm{ES}=0.61$, Figure $2(\mathrm{c})$ ) scores compared to controls, and the effect sizes were considered large. Copers also demonstrated poorer visual memory $(t=2.669, \mathrm{p}=0.025$, $E S=1.06$ ) compared to controls. Inspection of the score categories revealed that the majority of participants were considered "above average" or "average" regardless of groups (Figure 3). However, CAI participants were more frequently categorized as "low average", "low" or "very low" across the neurocognitive domains. Specifically, control participants fell into these categories in only $8.3 \%$ of instances, whereas $18.6 \%$ of coper and $21.4 \%$ of CAl participants were categorized as "low average", "low" or "very low." 

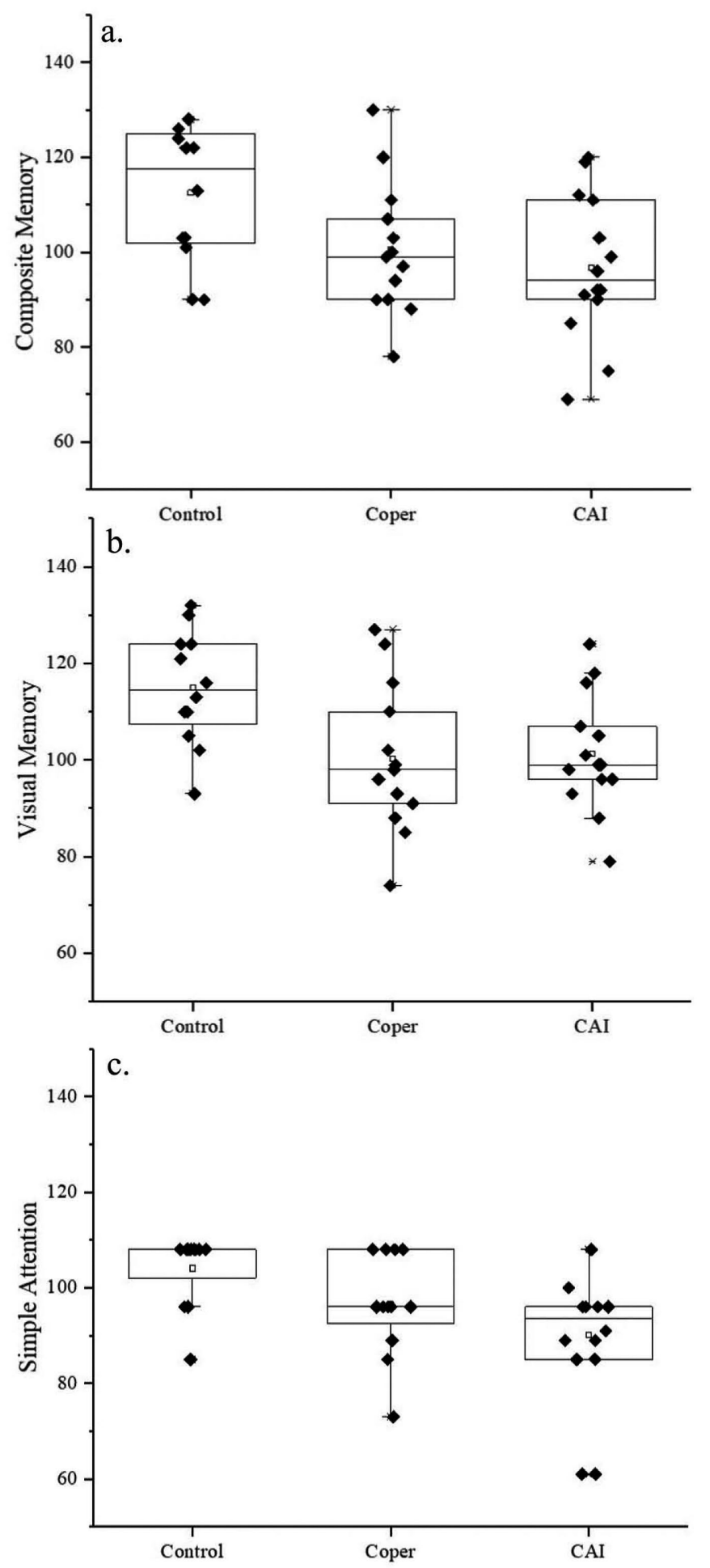

Figure 2. Figure 2 Boxplots with patient-level data of composite memory. (a) Visual memory (b) and Simple attention (c) in the control, coper and chronic ankle instability groups. 


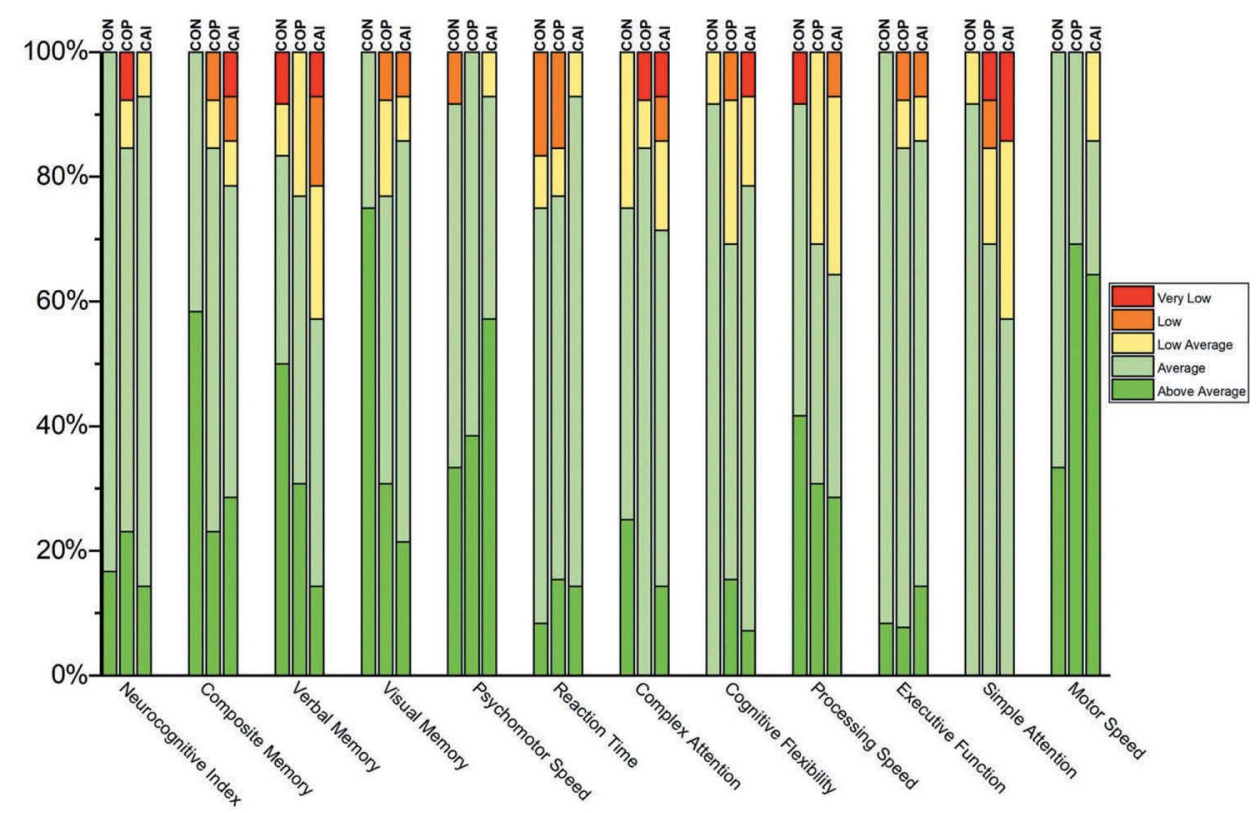

Figure 3. Percentage of control (CON, $n=14)$, coper (COP, $n=13)$, and chronic ankle instability (CAl, $n=14)$ participants that fell in the "above average", "average", "low average", "low", and "very low" ranges for each neurocognitive domain.

\section{Discussion}

The results of this study indicate that males with CAI demonstrated significantly lower levels of neurocognitive function, particularly related to memory and attention, relative to male healthy control participants. A combination of deficits in memory and attention could have an influence on recurrent ankle injuries and contribute to the poor outcomes associated with CAl. Neurologically, attention ties to visual encoding and memory, it is axiomatic that one has to pay attention to encode information. The combined functions are more likely to affect functional behaviour than either one alone. Further, the lower memory and attention scores align with previous research, which supports a potential link between neurocognitive function and musculoskeletal injury (Brooks et al., 2016; Lynall et al., 2017; McDonald et al., 2019; Swanik et al., 2007). This has implications for both the prevention and treatment of lower extremity injuries in athletic populations. 
Subtle decreases in attention and visual memory, which involve figure and shape recognition, may contribute to injury risk during movement and sporting activities in the presence of increased environmental stimuli. Slight performance changes in these areas may reduce spatial awareness and the ability to rapidly recognize environmental obstacles, which may decrease the threshold for instability or feelings of giving way. Swanik and colleagues postulated those with noncontact ACL injuries suffered from a "spatial disorientation" or loss of situational awareness interrupting motor programmes during highstimuli situations during physical activity (Swanik et al., 2007). Participants in our study demonstrated similar magnitude impairments in visual memory, further supporting a link between a history of musculoskeletal injury and neurocognitive function. However, all current research is cross-sectional in nature and does not clearly establish a cause-effect relationship between neurocognitive test performance and lower extremity injury. In addition, participants in these studies are still physically-active and the majority are not classified as "impaired" according to normative values. Although from a statistical standpoint the effect sizes were considered large, $92 \%$ of the healthy controls in our study fell into "average" or better normative categories, while $79 \%$ of CAI participants were classified in these groups (Figure 3). Thus, while more CAI participants would be considered "Iow average" or "very low" by normative standards on the CNSVS, the majority are not considered to have neurocognitive "impairment". Exploring how injury may impact neurocognitive function, as well as how it prospectively relates to injury risk in physically-active patients, are areas for future research.

Sport involves activities which require high-level cognitive processing. During a sporting event, playersmust react to a number of extrinsic stimuli including the objective, teammate and opponent movement, rapid changes in projectile direction, environmental obstacles and surface changes. These require the rapid integration of visual memory and spatial orientation in order to react appropriately as fast as possible. Additionally, the capacity to regulate sensory information properly may be inhibited by alterations in attentional capacity and potentially expose those with CAI to further injury. While no movement was conducted during the present study in conjunction with the neurocognitive tasks, we may be able to glean insight from 
previous work investigating dual-task paradigms, which attempt to stress higher level processing centres by making individuals perform multiple tasks at the same time. As highlighted in a recent systematic review, several studies involving dual-tasking have been completed in CAl populations (Burcal et al., 2019). A majority of these studies found individuals with CAl exhibit a deficiency in dualtask performance capability in relation to healthy individuals during the cognitive loading conditions (Burcal et al., 2019). Many of these studies suggest that those with CAI have an increased reliance on attention or experience difficulty with self-regulation, especially during activities (e.g. serial subtractions, Stroop Tests, etc.) which require significant attentional resources. Thus, patients with CAI may suffer from a deficient capacity to process a high volume of extrinsic and intrinsic information, which results in a sudden loss of ankle stability. The results of the present study add to previous research utilizing dual-tasks in patients with CAl, which demonstrate that participants with CAI have a poorer ability to properly regulate their attentional resources when compared to healthy counterparts.

The only significant finding regarding copers were that they demonstrated a decreased visual memory compared to controls with a large effect size, otherwise there were no statistically significant differences in neurocognitive profiles compared to controls and those with CAI. However, when assessing Figures 2 and 3 , it is clear that the neurocognitive scores of the copers fell between the control group and the group with CAI. Additionally, around $18 \%$ of all scores for coper participants fell within the "low-average", "low" and "very low" normative categories, which again falls between the control and CAI groups. This perhaps introduces an interesting dichotomy within the neurocognitive data, where copers fall on a continuum, with some copers behaving similarly to controls, while others align more closely to the CAI group. This has also been seen in several studies assessing a variety of factors among controls, copers and CAI, where results regarding copers are often inconclusive (Brown, Rosen, \& Ko, 2015; Holland, Needle, Battista, West, \& Christiana, 2019; Houston et al., 2015). Furthermore, based on recent prospective studies regarding ankle sprains (McDonald et al., 2019) and ACL injuries (Swanik et al., 2007) these deficiencies in neurocognitive function may be innate in these individuals and not acquired due to the injury. In addition, the coper and CAI group may have been too similar as some coper participants reported having 
more than one ankle sprain. This may help to explain some of the lack of differences between the groups. While it's difficult to speculate regarding the neurocognitive profiles in coper participants, this subset of coper participants with lower levels of neurocognitive function may be more susceptible to developing CAI in the future. This may warrant future consideration for researchers and clinicians.

\section{Limitations}

We acknowledge several limitations with the current study including the overall generalizability of the results, particularly related to the age and gender of the participants. As this study only included young adult males, it may not be generalizable to younger, older or female populations. Another limitation includes the effect of neurocognitive function plays on movement patterns as it pertains to at-risk profiles. As neurocognitive tests were completed sitting on a computer, the impact of neurocognitive function on motor control needs to be further investigated.

\section{Clinical implications}

Based on the findings, clinicians may want to consider exploring ways to provide increasing neurocognitive stimuli to rehabilitation programmes aimed at challenging patients throughout the recovery process. While traditional rehabilitation protocols incorporate some components of stimuli manipulation through visual inputs (e.g. closing eyes during balance) or task complexity (e.g. ball toss/catch), stimulating patients with neurocognitive challenges are less wide-spread (Needle \& Rosen, 2017). Recent literature has suggested a framework for neuroplastic intervention through visual training aimed at improving outcomes in ACL injury populations (Grooms, Appelbaum, \& Onate, 2015). Additionally, visuomotor training integrated in an injury prevention programmes for football athletes has shown promising evidence for neurocognitive improvements, yet the effectiveness for injury prevention, particularly for ankle injury and CAI populations is unclear and has not been established (Wilkerson, Simpson, \& Clark, 2017). However, much of the literature remains unclear in terms of protocols, dosage and types of neurocognitive interventions which may be most effective at reducing ankle injuries. 


\section{Conclusions}

In conclusion, males with CAI demonstrated several neurocognitive performance deficiencies relative to control participants, particularly related to memory and attention. This may limit patients with CAI in their ability to process a high volume of environmental information, which results in repeated episodes of ankle instability. Although the effect sizes were considered large, caution with this data is necessary as, if taken in isolation, the average standardized scores across all groups would fall solely within the "average" or "above average" range when compared to the general population and observing the clinical output reports. Indeed, this does lead to several limitations with the current data set including the generalizability of the results. Future studies should elucidate the role neurocognitive function plays in CAI movement behaviour as well as determine if neurocognitive training will reduce the risk of reinjury rates in individuals with CAI.

Disclosure statement - No potential conflict of interest was reported by the authors.

Funding - Funding for this project was provided by the National Institutes of Health [P20 GM109090] and Mid- American Athletic Trainers Association.

\section{References}

Brooks, M. A., Peterson, K., Biese, K., Sanfilippo, J., Heiderscheit, B. C., \& Bell, D. R. (2016). Concussion increases odds of sustaining a lower extremity musculoskeletal injury after return to play among collegiate athletes. American Journal of Sports Medicine, 44(3), 742-747.

Brown, C. N., Rosen, A. B., \& Ko, J. (2015). Ankle ligament laxity and stiffness in chronic ankle instability. Foot \& Ankle International. / American Orthopaedic Foot and Ankle Society [and] Swiss Foot and Ankle Society, 36(5), 565-572. PMID: 31039184.

Burcal, C. J., Needle, A. R., Custer, L., \& Rosen, A. B. (2019, May 7). The effects of cognitive loading on motor behavior in injured individuals: A systematic review. Sports Medicine, 49, 1233-1253. [Epub ahead of print].

Burcal, C. J., \& Wikstrom, E. A. (2016). Cognitive loading-induced sway alterations are similar in those with chronic ankle instability and uninjured controls. Gait \& Posture, 48, 95-98. PMID: 27477716. 
Cohen, J. (1992). Statistical power analysis. Current Directions in Psychological Science, 1(3), 98-101.

Covassin, T., Swanik, C. B., Sachs, M., Kendrick, Z., Schatz, P., Zillmer, E., \& Kaminaris, C. (2006). Sex differences in baseline neuropsychological function and concussion symptoms of collegiate athletes. British Journal of Sports Medicine, 40(11), 923-927. PMID: 16990442.

Field, A. (2005). Discovering statistics using SPSS (2nd ed.). Thousand Oaks, CA, US: Sage Publications, Inc.

Fritz, C. O., Morris, P. E., \& Richler, J. J. (2012). Effect size estimates: Current use, calculations, and interpretation. Journal of Experimental Psychology, 141(1), 2-18. PMID: 21823805.

Gribble, P. A., Delahunt, E., Bleakley, C., Caulfield, B., Docherty, C., Fourchet, F., ... Wikstrom, E. (2014). Selection criteria for patients with chronic ankle instability in controlled research: A position statement of the International Ankle Consortium. British Journal of Sports Medicine, 48(13), 1014-1018. PMID: 24255768.

Grooms, D., Appelbaum, G., \& Onate, J. (2015). Neuroplasticity following anterior cruciate ligament injury: A framework for visual-motor training approaches in rehabilitation. Journal of Orthopaedic \& Sports Physical Therapy, 45(5), 381393. PMID: 25579692.

Gualtieri, C. T., \& Johnson, L. G. (2006). Reliability and validity of a computerized neurocognitive test battery, CNS vital signs. Archives of Clinical Neuropsychology, 21(7), 623-643. PMID: 17014981.

Hershkovich, O., Tenenbaum, S., Gordon, B., Bruck, N., Thein, R., Derazne, E., ... Afek, A. (2015). A large-scale study on epidemiology and risk factors for chronic ankle instability in young adults. The Journal of Foot and Ankle Surgery, 54(2), 183-187. PMID: 25135102.

Hertel, J., \& Kaminski, T. W. (2005). Second international ankle symposium summary statement. The Journal of Orthopaedic and Sports Physical Therapy, 35(5), A2-A6. PMID: 15966544.

Hiller, C. E., Refshauge, K. M., Bundy, A. C., Herbert, R. D., \& Kilbreath, S. L. (2006). The Cumberland ankle instability tool: A report of validity and reliability testing. Archives of Physical Medicine and Rehabilitation, 87(9), 1235-1241. PMID: 16935061.

Holland, B., Needle, A. R., Battista, R. A., West, S. T., \& Christiana, R. W. (2019). Physical activity levels among rural adolescents with a history of ankle sprain and chronic ankle instability. PloS One, 14 (4), e0216243. PMID: 31039184.

Houston, M. N., Hoch, J. M., \& Hoch, M. C. (2015). Patient-reported outcome measures in individuals with chronic ankle instability: A systematic review. Journal of Athletic Training, 50(10), 1019-1033. PMID: 26332028.

Hubbard-Turner, T., \& Turner, M. J. (2015). Physical activity levels in college students with chronic ankle instability. Journal of Athletic Training, 50(7), 742747. PMID: 25898110. 
Hung, Y. J., \& Miller, J. (2016). Extrinsic visual feedback and additional cognitive/ physical demands affect single-limb balance control in individuals with ankle instability. World Journal of Orthopedics, 7(12), 801-807. PMID: 28032032.

Lynall, R. C., Mauntel, T. C., Pohlig, R. T., Kerr, Z. Y., Dompier, T. P., Hall, E. E., \& Buckley, T. A. (2017). Lower extremity musculoskeletal injury risk after concussion recovery in high school athletes. Journal of Athletic Training, 52(11), 1028-1034. PMID: 29140128.

McDonald, A. A., Wilkerson, G. B., McDermott, B. P., \& Bonacci, J. A. (2019, May). Risk factors for initial and subsequent core or lower extremity sprain or strain among collegiate football players. Journal of Athletic Training, 54(5), 489-496. PMID: 31084505.

Nazareth, A., Huang, X., Voyer, D., \& Newcombe, N. (2019). A meta-analysis of sex differences in human navigation skills. Psychonomic Bulletin \& Review. 26(5), 1503-1528. PMID: 31270765.

Needle, A. R., \& Rosen, A. B. (2017). Ligament injury changes brain function: Now let's think about it. Athletic Training \& Sports Health Care, 9(5), 198-199.

Rahnama, L., Salavati, M., Akhbari, B., \& Mazaheri, M. (2010). Attentional demands and postural control in athletes with and without functional ankle instability. The Journal of Orthopaedic and Sports Physical Therapy, 40(3), 180-187. PMID: 20195021.

Roos, K. G., Kerr, Z. Y., Mauntel, T. C., Djoko, A., Dompier, T. P., \& Wikstrom, E. A. (2017). The epidemiology of lateral ligament complex ankle sprains in national collegiate athletic association sports. The American Journal of Sports Medicine, 45(1), 201-209. PMID: 27573356.

Rosen, A., Ko, J., \& Brown, C. (2016). A multivariate assessment of clinical contributions to the severity of perceived dysfunction measured by the cumberland ankle instability tool. International Journal of Sports Medicine, 37(14), 1154-1158. PMID: 27706549.

Rosen, A. B., Than, N. T., Smith, W. Z., Yentes, J. M., McGrath, M. L., Mukherjee, M., \& Maerlender, A. C. (2017). Attention is associated with postural control in those with chronic ankle instability. Gait \& Posture, 54, 34-38. PMID: 28254684.

Shah, S., Thomas, A. C., Noone, J. M., Blanchette, C. M., \& Wikstrom, E. A. (2016). Incidence and cost of ankle sprains in united states emergency departments. Sports Health, 8(6), 547-552. PMID: 27474161.

Shiravi, Z., Talebian, S., Hadian, M. R., \& Oliaie, G. R. (2017, Jan). Effect of cognitive task on postural control of the patients with chronic ankle sprain. Journal of Bodywork and Movement Therapies, 21 (1), 58-62. PMID: 28167191.

Springer, S., \& Gottlieb, U. (2017). Effects of dual-task and walking speed on gait variability in people with chronic ankle instability: A cross-sectional study. BMC Musculoskeletal Disorders, 18, 316. PMID: 28732483.

Swanik, C. B., Covassin, T., Stearne, D. J., \& Schatz, P. (2007). The relationship between neurocognitive function and noncontact anterior cruciate ligament injuries. The American Journal of Sports Medicine, 35(6), 943-948. PMID: 17369562. 
Tanen, L. 1., Docherty, C. L., Van Der Pol, B., Simon, J., \& Schrader, J. (2014, Feb 7). Prevalence of chronic ankle instability in high school and Division I athletes. Foot \& Ankle Specialist, 7(1), 37-44. PMID: 24287210.

Tavakoli, S., Forghany, S., \& Nester, C. (2016). The effect of dual tasking on foot kinematics in people with functional ankle instability. Gait \& Posture, 49, 364370. PMID: 27494304.

Valderrabano, V., Hintermann, B., Horisberger, M., \& Fung, T. S. (2006). Ligamentous posttraumatic ankle osteoarthritis. The American Journal of Sports Medicine, 34(4), 612-620. PMID: 16303875.

Weiss, E., Kemmler, G., Deisenhammer, E., \& Margarete, D. (2008). Sex differences in cognitive functions. Personality and Individual Differences, 35(4), 863-875.

Welton, K. L., Kraeutler, M. J., Pierpoint, L. A., Bartley, J. H., McCarty, E. C., \& Comstock, R. D. (2018). Injury recurrence among high school athletes in the United States: A decade of patterns and trends, 2005-2006 through 20152016. Orthopaedic Journal of Sports Medicine, 6(1), 2325967117745788. PMID: 29318177.

Wikstrom, E. A., \& Brown, C. N. (2014). Minimum reporting standards for copers in chronic ankle instability research. Sports Medicine (Auckland, N.Z.), 44(2), 251-268. PMID: 24122774.

Wilkerson, G. B., Simpson, K. A., \& Clark, R. A. (2017). Assessment and training of visuomotor reaction time for football injury prevention. Journal of Sport Rehabilitation, 26(1), 26-34. PMID: 27632871. 